\title{
O CONSUMO DE FIBRAS ALIMENTARES É ADEQUADO EM CRIANÇAS COM DIFICULDADES ALIMENTARES?
}

\section{Pôster}

Autores deste trabalho:

Rita de Cassia de Souza Fernandes: Centro de Dificuldades Alimentares do Instituto de Pesquisa e Ensino em Saúde Infantil - PENSI

Priscila Maximino Passos de Oliveira: Centro de Dificuldades Alimentares Infantis do Instituto de Pesquisa e Ensino em Saúde Infantil

- PENSI

Raquel Ricci: Centro de Dificuldades Alimentares do Instituto de Pesquisa e Ensino em Saúde Infantil - PENSI

Rachel Helena Vieira Machado: Centro de Dificuldades Alimentares do Instituto de Pesquisa e Ensino em Saúde Infantil - PENSI

Cláudia de Cássia Ramos: Centro de Dificuldades Alimentares do Instituto de Pesquisa e Ensino em Saúde Infantil - PENSI

Maria Júlia Russo de Carvalho: Centro de Dificuldades Alimentares do Instituto de Pesquisa e Ensino em Saúde Infantil - PENSI

Mauro Fisberg: Centro de Dificuldades Alimentares do Instituto de Pesquisa e Ensino em Saúde Infantil - PENSI

Área do Trabalho: Nutrição

Data da submissão: 25/07/2018 às $12: 54$

\section{Justificativa}

Crianças com dificuldades alimentares (DA) tendem a restringir frutas, legumes e verduras, o que pode impactar em baixa ingestão de fibras alimentares, importantes para prevenir o risco de doenças crônicas e desordens gastrintestinais.

\section{Objetivo(s)}

Comparar o consumo de fibras alimentares de crianças com DA às recomendações para idade e analisar o perfil de adequação de consumo.

\section{Método(s)}

A amostra foi composta por 76 prontuários de crianças de 12 meses a 13 anos com diagnóstico de DA e sem uso de suplementação dietética, sendo coletados a idade (meses/anos) e o consumo médio de fibras, após cálculo de diário alimentar de três dias. Foram analisados o consumo absoluto (g/dia) e o consumo ajustado (g/1000 kcal) de fibras totais de acordo com os critérios propostos pela Academia Americana de Pediatria (AAP) (idade $+5 \mathrm{~g}$ ) e pelo Institute of Medicine (IOM) (consumo ideal $14 \mathrm{~g} / 1000 \mathrm{kcal}$ para todos os grupos etários). O consumo foi classificado em "possivelmente adequado" e "possivelmente inadequado". Foram utilizados o teste ANOVA, T-Student e correlações com nível de significância menor que $5 \%$. A pesquisa foi aprovada por Comitê de Ética, sob-registro CAAE 32939314.0.0000.5567.

\section{Resultado(s)}




\section{$4^{\circ}$ Congresso Internacional Sabaró \\ 13 a 15 de \\ 13 a 15 de
setembro de 2018}

Hotel Maksoud Plaza
Alameda Campinas, 150

A média de consumo absoluto da amostra foi de $8,4 \pm 5,3 \mathrm{~g} /$ dia e de consumo ajustado de 6,4 $\pm 3,2 \mathrm{~g} / 1000 \mathrm{kcal}$. Quanto ao consumo absoluto de fibras, $43 \%$ das crianças de 1- 3 anos, $66,7 \%$ das crianças entre 4-8 anos e 71,4\% das crianças entre 9 -13 anos consomem volume de fibra dietética inferior às recomendações para cada grupo etário. Quanto ao consumo ajustado de fibras, cerca de $5 \%$ das crianças entre 4-8 anos apresentaram consumo ajustado compatível com o esperado, estando todo o restante (inclusive dos demais grupos etários) com ingestão insuficiente. 0 consumo (absoluto e ajustado) não variou segundo gênero $(p>0,92)$ ou grupo etário ( $p>0,11$ Anova; R Pearson $<0,27$ ).

\section{Conclusão (ões)}

Houve consumo possivelmente inadequado de fibras pelas crianças com DA, o que cabe maior atenção por parte da família e da equipe multidisciplinar. 